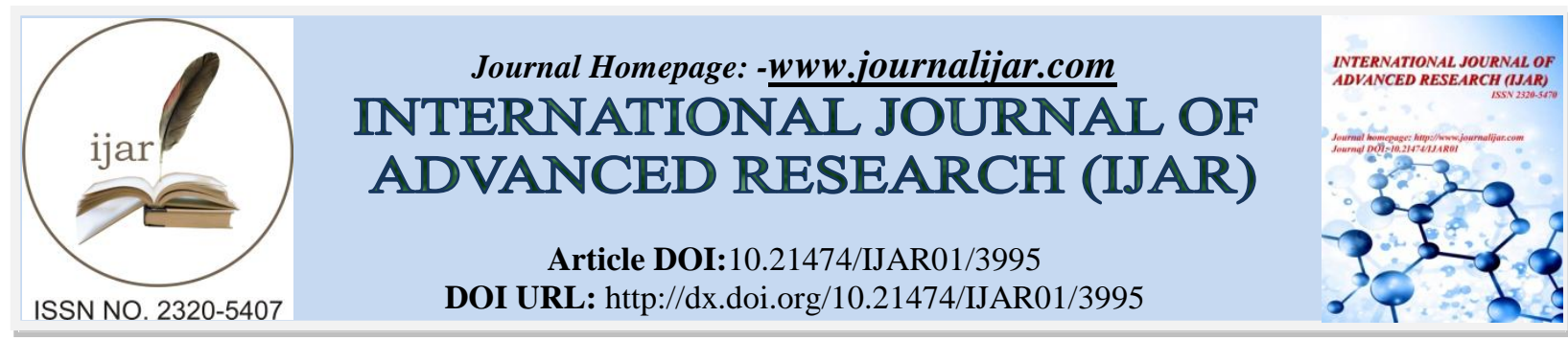

RESEARCH ARTICLE

\title{
A STYLISTIC STUDY OF THE USE OF ADJECTIVES IN SHAPIRO'S “AUTO WRECK”
}

\section{Dr. Hoshang Farooq Jawad ${ }^{1}$ and Dr. Mukhalad Malik Yosif ${ }^{2}$.}

1. Professor Assistant- Department of English- Faculty of Basic Education-Sulaimaniya University.

2. Lecturer- Department of English- Cihan University- Sulaimaniya.

\section{Manuscript Info}

Manuscript History

Received: 18 February 2017

Final Accepted: 22 March 2017

Published: April 2017

Key words:-

adjectives, semantic analysis, syntactic analysis, stylistics,

\begin{abstract}
The current study is an empirical investigation of the use of adjectives in the poem Auto Wreck by Karl Shapiro. The paper attempts at illustrating how adjectives are exploited by the poet so as to achieve various literary purposes including signifying the theme, depicting the main events and creating a sense of attraction and suspension in the readers' minds. The use of adjectives is significant in fulfilling such purposes clearly and efficiently. They represent the linguistic forms and the literary meaning to be conveyed throughout the entire poem. The paper reveals that using adjectives is a stylistic tendency used by Shapiro to achieve his literary purposes in showing the theme of the poem and to a large extent showing necessary and relevant details.
\end{abstract}

Copy Right, IJAR, 2017,. All rights reserved.

\section{Introduction:-}

Generally speaking, adjectives are words such as tall, round, happy, etc that describe nouns (persons or a thing) in sentences. In grammar, an adjective is a word whose main syntactic role is to modify noun or pronoun, giving more information about the noun or pronoun's referent. Collectively, adjectives form one of the traditional English eight parts of speech though linguists today distinguish adjectives from words such as determiners that also used to be considered adjectives. The current paper aims at investigating the importance of this word category in poetic language as a stylistic marker which has a great role in achieving various literary purposes. The paper examines how adjectives are used in the poem 'Auto Wreck' by Karl Shapiro (published in 1968). The study is mainly concerned with the syntactic and semantic analysis of adjectives as exploited in the poem so as to relate it to the stylistic tendency that the poet uses to express the theme and depict the main literary devices used in the poem. The model of analysis to be relied on in this study is adopted form Leech and Short (1981). In general, the paper aims at relating the linguistic use of adjectives to the stylistic tendency which distinguishes the style of writer in this specific poem.

\section{Definitions of Adjectives:-}

Adjectives are characterized as expressions "that alter, clarify, or adjust the meaning contributions of nouns", in order to allow for the expression of "finer gradations of meaning" than are possible through the use of nouns alone (Huddleston and Pullum 2002:526). According to Crystal (2008), adjectives which might be abbreviated as (A, adj, ADJ) belong to the grammatical category of words referring to the main set of items which specify the attributes of nouns from a formal point of view. Crystal states that the narrow and broad presentations of the term "adjectives" will be found in grammars. Generally speaking, an adjective could include everything between determiner and the noun, in such a phrase as the vicar's fine oldgarden chair ; but many linguists prefer to restrict it to the items which fulfill more or all of the above standards (to include only fine and old ), in this example, the other items being called' 'adjective - like " or 'adjectives ' (ibid). Radford et al. (2009) argue that adjectives typically refer to 
properties which people or things possess and they are used to modify nouns, e.g. happy man, noisy engine they also affirm that adjectives share with articles the property of appearing in front of a noun, if an article and an adjective both combine with a noun, they do so in a fixed order (a happy man, *happy a man, the noisy engine, * noisy the engine). When stating the definitions of adjectives, it is very necessary to mention the major forms that adjectives have. Alexander (1997:106) classifies forms of adjectives into: "a. Quality: a beautiful dress; nice day b. Size: a big car; a small coin. c. Age: a new handbag; a young man. d. Temperature: a cold evening; a hot weather. e. Shape: a round table; a square box. f. Color: blue eyes; a white house. g. Origin: a Japanese camera; a Swiss watch". This classification is very important as it is highly connected to the stylistic analysis of the poem later on.

\section{Syntactic and Semantic Analysis of Adjectives:-}

At a general level, adjectives gain this capability in virtue of two main characteristics, one of which is semantic and one of which is syntactic. On the semantic side, they introduce properties. (Whether they actually denote properties is a question we will address in detail below.) On the syntactic side, they are able to function as modifiers, and so may (with some restrictions) combine recursively with nouns. At the syntactic level, and for the purpose of verifying the specific aims of the study, adjectives comprise two main kinds: attributive and predicative. Syntactically speaking, an attributive signifies the role of "adjective" when it modifies the head of a noun phrase for example, red has attributive function in "the red chair". On the other hand, the predicative adjective function as a complement as in "the chair is red".In other words, the terms attributive and predicative refer to the syntactic positions and functions of an adjective in a phrase or sentence. It is possible to state that an adjective is attributive or is used attributively when it modifies a noun (and is therefore part of noun phrase), while it is a predicative or predicatively when it occurs directly after a linking verb (Crystal 2008). At the semantic level of analysis Quirk et al (1985:21) classify adjectives semantically into: "a-stative/dynamic: Adjectives, in fact, are characterized as stative, but many of them are dynamic, adjectives like tall cannot be used with progressive aspect or with the imperative He's being tall ,be tall" . Dynamic adjectives, on the other hand, can be used in both respects as for instance, the use of 'careful' as a dynamic adjective: He's being careful, be careful. "b-Gradable/ non- gradable : Most adjectives are graded ,in other words, they can be modified by adverbs to express the degree of the adjective . Adjectives that accept comparison have this feature: tall /taller/ tallest, beautiful /more beautiful / most beautiful and other forms of intensification: very young, so plain, extremely useful" (ibid). Quirk and Greenbaum (1973) refer to additional terms used to describe adjectives semantically, they define the term inherent as an adjective that characterizes the referent nondirectly; in "that old man", 'old' is central adjectives, the opposite of young which means that it is possible to relate 'that old man' to 'the man that is old'. Non -inherent term refers to those adjectives that do not characterize that referent of noun directly; in " an old man friend, old as an adjective which refers to the (friendship) not to the (man) so it is possible to say "an old friend, but not "the friend is old". Heyvaert (2010) states that within the semantic analysis of adjectives, there is a general tendency to divide adjectives into two main categories: descriptive and relational adjectives. The latter have only a 'relational' semantic content: they denote a relation between their subject and another nominal concept. So, for instance, 'chemical' has as its only semantic content 'related to chemistry'.

This distinction however meets some problems. The decision to put a particular adjective in one of both categories is sometimes slightly arbitrary. And some words that formally look like relational adjectives have a fairly rich meaning content. So, for instance, Orwellian is not just 'related to Orwell', but 'being like the totalitarian world in Orwell's 1984'.As far as the category of descriptive adjectives is concerned, it is possible to detect some further distinctive disagreements, creating subcategories. Adjectives may be absolute or gradable (an opposition that correlates with the presence or absence of comparative and superlative), they may have a scalar meaning (like adjectives denoting a size) or not or they can have an extensional or an intensional meaning (where the distinguished categories are called intersective vs. non-intersective adjectives). The latter distinction has to do with use differences as is shown by heavy in heavy suitcase and heavy drinker, where in the first case the thing itself is modified, and in the second case not the person but the property 'drinker'.

\section{Stylistics:-}

Since the paper is intended to clarify the stylistic significance of the use of adjectives in poetry ('Auto Wreck' poem), this section is entirely devoted to illustrating stylistics and the applicable linguistic levels upon which it may operate; the syntactic and semantic levels as it is the scope of the paper. Stylistics is best defined by Short (1996: 1) as "an approach to the analysis of(literary) texts usinglinguistic description." He mentions that "There are also linguists who examine non-literary texts . "Stylistics has its root in the formalistic school of literary criticism emerged inRussia early in the twentieth century. Formalism "erected on the foundationslaid by the SYMBOLIST 
movement a critical method that posited theautonomy of the work of art and the discontinuity of the language ofliterature from other kinds of language"(Child and Fowler,2006: 93). Crystal(2008: 195) strictly links the term formalism, or to be exact formalist, tostylistics" A term applied in stylistics to any approach which regards a text asa formal object of study, with an internal structure that can be objectively andformally identified." Thornborrow and Wareing (1998:2) limit some key aspects of stylistics as:

the use of linguistics (the study of language) to approach literary texts.

-the discussion of texts according to objective criteria rather than according purely to subjective and impressionistic values.

-emphasis on the aesthetic properties of language (for example, the way rhyme can give pleasure).

Leech and Short (1981:74) illustrate the task of stylistic analysis as "an attempt to find the artistic principles underlying a writer choice of language. All writers, and for that matter, all texts, have their individual qualities." Short (1996:xii) argues that the priority in analysing a text stylistically in current times "has been to try to understand the relationship between the literary text, on one hand, and how we understand it, and affected by it, on the other." Thornborrow and Wareing (1998:4) explain that "One of the main functions of early stylistics was to explain how the „meaningee of a text was created through the writer's linguistic choices.”Niazi and Guatam (2010:109) see that the main aim of stylistic analysis is "to provide as detailed description as possible of the work in question." Leech and Short (1981:119f) distinguish three levels of organization whichtogether form the expression plan of language. These levels are: "SEMANTICS, SYNTAX and PHONOLOGY. While the semantic level is thelevel of meaning, the syntactic level is the level of identifying language structure, form and function of word category within sentences and so on. For achieving the aim of the paper, only the semantic and syntactic levels of analysis are considered."

\section{Model of Analysis:-}

The model adopted in analyzing the two poems is drawn heavily on Leechand short (1981)and Short (1996). The framework of this eclectic model can be within the following step:

1. Providing some background information about the poet and the poem.

2. Giving a general understanding of the poem under analysing.

3. Initiating a linguistic stylistic analysis within the level of semantic analysis (lexis) by stating the used content words (the use of the adjectives) to highlight the significance of their frequency in the poem as a stylistic marker used by the writer and to relate them to the theme of the poem in addition to clarify how they largely contribute in depicting the literary devices used throughout the entire poem. The other level of analysis is the syntactic one which comprises clarifying the type and function of the used adjectives. In both levels, the aim is to relate the linguistic analysis of the adjectives semantically and syntactically to the stylistic tendency which the writer is applying throughout his poem.

\section{Data Analysis:-}

Before embarking on data analysis which is the ultimate aim of the current study, it is a prerequisite to explain the poem so as to meet the requirements of the analysis. Stylistically speaking, "Auto Wreck" is in free verse with four stanzas. There are two themes that run through the poem. The first is the detached efficiency of the ambulance in motion, contrasted by the second theme, the fragile, easily broken humans, who are cut down randomly and at times violently. There are two conspicuous strains of imagery running through this poem. One is physical injury while the other recurring symbol is light (Aiken, 1968). The poem has specific major themes to be conveyed and, in fact, it is structured to illuminate the theme of contrast between order and chaos; how humans counter a perplexing situation with a surplus ofreason. Order and disorder are not given equal representation in the poem because the chaotic action, which may have only taken a few seconds anyway, is over when the poem begins: the occurring actions are taken to gain control over the chaos (ibid). On the other hand, the speaker (the narrator of the poem) is confusedeven somehow annoyed - by the care that everyone is taking to restore order because it totally contradicts the basic fact that order can never be restored once the line of death has been crossed (Stauffer, 1974). Turning to the central aim of the paper; namely, the analysis of the poem as far as the use of adjectives is concerned, the total number of the adjectives used in the poem is twenty. Those adjectives include only the ones which are syntactically classified as pure adjectives and do not include other forms functioning as adjectives. As far as the syntactic analysis is concerned, those adjectives are grouped into the syntactic level of attributive adjectives, i.e. they have attributive function of noun modifiers in the noun phrases with which they appear as in the following table: 


\begin{tabular}{|l|l|l|}
\hline The Attributive Adjective & The Modified Noun & Line No. \\
\hline quick, soft, silver & Bell & 1 \\
\hline ruby & Flare & 2 \\
\hline red & Light & 3 \\
\hline top & Speed & 4 \\
\hline heavy & Curve & 6 \\
\hline little & Hospital & 10 \\
\hline terrible & Cargo & 12 \\
\hline empty & Husks & 22 \\
\hline $\begin{array}{l}\text { stubborn } \\
\text { common }\end{array}$ & $\begin{array}{l}\text { saw } \\
\text { sense }\end{array}$ & 27 \\
\hline $\begin{array}{l}\text { grim } \\
\text { banal }\end{array}$ & $\begin{array}{l}\text { joke } \\
\text { resolution }\end{array}$ & 28 \\
\hline richest & Horror & 30 \\
\hline occult & Mind & 36 \\
\hline $\begin{array}{l}\text { expedient } \\
\text { wicked }\end{array}$ & $\begin{array}{l}\text { stones } \\
\text { stones }\end{array}$ & 39 \\
\hline
\end{tabular}

On the other hand, few adjectives in the entire poem are syntactically used as predicative functioning as complements as in line 22:

"our throats were tight" where the adjective 'tight' occurs after an auxiliary functioning as subject complement. In line 31: "Already old, the question who shall die?", the adjective 'old' may have a vague syntactic function where it may refer to 'an old question' functioning as noun modifier or as subject complement if interpreting as 'the question is already old'. Consequently, the stylistic analysis of the use of adjectives whether attributively or predicatively indicate that the writer relies heavily on modification structure through the use of those adjectives so as to specify, signify, describe or add detailed information to the nouns which they modify. In this case, the syntactic behavior of the adjectives functioning as noun modifiers determine the stylistic tendency of the writer to enrich the main themes and ideas (through the use of nouns) with supporting, detailed and more explanatory ideas through the use of modifications (attributive adjectives) so as to depict the poem and clarify the themes in a way that is proper to the stylistic tendency of the writer. The other stylistic analysis which is the most significant is the semantic analysis and this clearly includes lexical analysis of adjectives as used in the poem stylistically. Throughout the entire poem, the semantic analysis of adjectives is largely attributed to the semantic feature of descriptive. In other words, adjectives are used descriptively to depict, illustrate and clarify the theme and the detailed meaning of the lines of the poem. But such descriptive use of adjectives is used stylistically to convey connotative meanings; an idea or feeling that a word (an adjective in this case) invokes in addition to its literal or primary meaning. This is definitely to achieve the literary purposes of the poet in his poetic use of language. For instance, in the second line, the poet uses 'ruby flare' which denotes a red sign and this connotes danger or an emergency. This is totally in contrast with the first line where the adjectives are used to bring about gentleness and harmony through the use of 'quick' and 'soft'. This might be related to the stylistics of the poem where the use of those contradictory adjectives which are connotatively used to describe two different situations is also related to conveying the themes of order 'quick soft' and disorder; 'ruby flare' and 'dark one'. The tone, which is a major part of the style of the poem, is also directly reflected by the use of such descriptive adjectives throughout the poem. In the third line, the ominous tone continues as an analogy is drawn between the flare and a part of the human body - an artery pulsing out red light, or blood, would be an artery cut open. In this line, the significance of the use of the adjective 'red' is giving the impression that something bad or unpleasant is going to happen. So the adjective of colour is used stylistically to describe what is beyond its denotation. In line 10, the ambulance is called "little hospital" and the use of the size adjective 'little' is connotatively significant bringing the order, sterility and control of the hospital environment to the crash scene to be contrasted later on to the disorder which is represented by the use of contrastive adjectives such as "terrible cargo" in line 12 where it is an announcement of the end of life and "wicked stones" in line 39. In certain cases, the use of adjectives semantically contrast the nouns which they modify and this refers to the stylistic tendency the poet intends to use so as to fulfill the literary purposes of the poem. For instance, in line 27 , the adjective grim 'denoting unsmiling' modifies joke and this is certainly a contrast between the lexical meaning of grim and that of joke. This is either due to stressing the theme of order and disorder or to create a sense of paradoxical use of adjectives with their modifiers. 


\section{Conclusion:-}

The use of adjectives in poetic language plays a significant role in identifying the stylistic tendency of the poet. Adjectives, as used in the poem 'Auto Wreck', comprise two levels of linguistic analysis; namely, the syntactic and the semantic levels. The two levels have a major role in identifying the style that Shapiro uses to fulfill his literary intentions throughout the entire poem. The syntactic and semantic manifestations of adjectives in the poem serve as the literary tools the poet uses to clarify his attitude towards the major theme of the poem. Syntactically speaking, adjectives are used attributively modifying the nouns with which they appear so as to add detailed explanation to the major events throughout the poem. As far as semantics is concerned, the lexical use of those adjectives is purely descriptive so as to depict the connotation side of the poem. Moreover, the semantic properties of the used adjectives elaborate the intention of the poet as far as the theme and the ideas he seeks to convey. It is possible to state the use of adjectives in this specific poem is one of the stylistic markers that distinguish Shapiro's poetic use of language.

\section{Bibliography:-}

1. Aiken, Conrad. (1968). "Karl Shapiro," in Collected Criticism. Oxford: Oxford University Press.

2. Alexander, J. (1992). Longman English Grammar. London: Longman.

3. Child, P and Fowler, E. (2006). The Routledge Dictionary of LiteraryTerms. London: Routledge.

4. Crystal,D. (2008). A Dictionary of Linguistics and Phonetics. Oxford: Blackwell.

5. Heyvaret, Frans. (2010).Proceedings of the 14th EURALEX International Congress: An outline for a semantic categorization ofadjectives. The Netherlands: Fryske Akademy.

6. Huddleston, R. and Pullum, K. (2002). The Cambridge Grammar ofthe English Language. Cambridge: Cambridge University Press.

7. Leech, G. and Short, M. (1981).Style in Fiction. London : Longman.

8. Niazi, N. and Gautam, R. (2007). How to Study Literature: Stylistics\&Pragmatics Approaches. Teheran: Rahnama Press.

9. Quirk, R., Greenbaum, S. Leech, G. and Svartvik, J. (1985). A Comprehensive Grammar of English Language. London: London Croup Limited.

10. Quirk, R., Greenbaum, S. (1973). A university Grammar of English. London: London Croup Limited.

11. Radford, A.; Martin, A; David; Herald, C. Andrew, S. ( 2009). Linguistics: An Introduction . Cambridge: Cambridge University Press.

12. Short, M. (1996).Exploring the Language of Poems, Plays and Prose. London: Longman.

13. Stauffer, Donald Barlow. (1974). A Short History of American Poetry. New York: E.P. Dutton \& Co.

14. Thornborrow, J. and Wareing, S. (1998).Patterns in Language: AnIntroduction to Language and Literary Style. London:Routledge. 